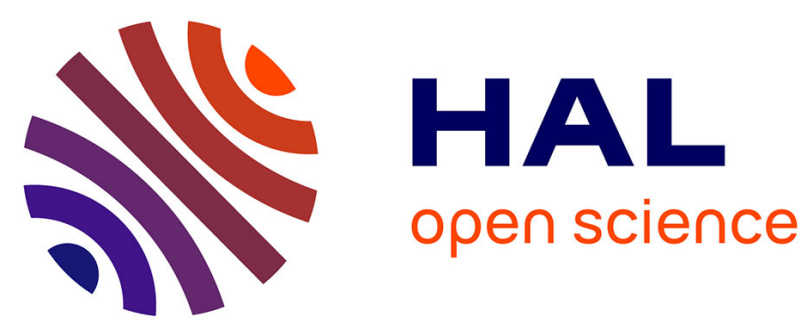

\title{
Immunotherapy in Alzheimer's Disease: Do We Have All the Pieces of the Puzzle?
}

Marie Sarazin, Guillaume Dorothée, Leonardo Cruz de Souza, Pierre Aucouturier

\section{- To cite this version:}

Marie Sarazin, Guillaume Dorothée, Leonardo Cruz de Souza, Pierre Aucouturier. Immunotherapy in Alzheimer's Disease: Do We Have All the Pieces of the Puzzle?. Biological Psychiatry, 2013, 74 (5), pp.329 - 332. 10.1016/j.biopsych.2013.04.011 . inserm-01876544v2

\section{HAL Id: inserm-01876544}

\section{https://www.hal.inserm.fr/inserm-01876544v2}

Submitted on 18 Sep 2018

HAL is a multi-disciplinary open access archive for the deposit and dissemination of scientific research documents, whether they are published or not. The documents may come from teaching and research institutions in France or abroad, or from public or private research centers.
L'archive ouverte pluridisciplinaire HAL, est destinée au dépôt et à la diffusion de documents scientifiques de niveau recherche, publiés ou non, émanant des établissements d'enseignement et de recherche français ou étrangers, des laboratoires publics ou privés. 


\section{Immunotherapy in Alzheimer's disease: do we have all the pieces of the puzzle?}

by

Marie Sarazin, Guillaume Dorothée, Leonardo Cruz de Souza, Pierre Aucouturier

The increasing global prevalence and societal cost of Alzheimer's disease (AD) explains the urge for a rapid development of an effective disease-modifying treatment able to stop the pathophysiological process. Among AD lesions, accumulation of amyloid $\beta(\mathrm{A} \beta)$ peptide may be considered the initial insult, with Tau hyperphosphorylation being a necessary downstream effect. $A \beta$ has thus been the main target of most recent therapeutic approaches. Among them, immunization against $\mathrm{A} \beta$ holds promise for clinical benefit - a promise supported by initial observations of favourable effects in experimental mouse models of AD. ${ }^{1-3}$

1. Disappointing clinical results of $A \beta$-specific immunotherapy

\subsection{Initial attempts of active vaccination}

The first anti-A $\beta$ vaccine (AN1792) tested in AD patients included full length A $\beta 42$ peptide with an adjuvant (QS1) that preferentially promotes $\mathrm{T}$ cell-mediated immune responses. The choice of such a Th1 adjuvant was likely related to previous experimental studies in mouse models, in which complete Freund's adjuvant (CFA) had been used. Large inter-individual differences were observed in the immune responses, with no more than $20 \%$ "antibody responders". Six percent of the patients developed severe meningoencephalitides likely due to activation of pro-inflammatory T cells. ${ }^{4,5}$ Although the AN1792 trial had to be interrupted because of these severe side effects, a globally favourable although modest effect could be 
demonstrated upon blind follow-up of the cohort for 12 months after stopping the treatment. ${ }^{4}$ The immunological mechanisms actually involved in these clinical effects remain unclear, as cellular immune responses to $\mathrm{A} \beta$ were not assessed in parallel to antibody responses. Patients with high antibody levels had less brain amyloid plaques, suggesting that antibodies cleared $\mathrm{A} \beta$ deposits, although this clearance did not prevent neurodegeneration nor improve the longterm clinical course. ${ }^{6}$

\subsection{Immunotherapy based only on anti-A $\beta$ antibodies}

Two types of strategies were developed in order to avoid the activation of any $\mathrm{T}$ cell response to $A \beta$. In both, antibodies specific for one single small peptide sequence of $A \beta$ were expected to recapitulate the therapeutic effects.

\section{Active "humoral-only" immunization}

Considering that activation of $A \beta$-specific $T$ cells were potentially harmful, second generation vaccines were designed for inducing strictly humoral responses to A $\beta$. Such vaccines were made up of small peptide sequences of $A \beta$ conjugated to a "carrier", i.e. an exogenous protein allowing the T-B cell cooperation, which is required for inducing an efficient antibody response. To date, only the results of the phase 1 study of CAD106, a vaccine made up of the $6 \mathrm{~N}$-terminal aminoacids of $\mathrm{A} \beta$ conjugated to multiple copies of a bacteriophage coat protein, have been reported: the vaccine induced the production of antibodies to $A \beta$ in $80 \%$ of the patients, without significant related side effects. ${ }^{7}$ Assessment of its protective effect is currently underway.

\section{Passive immunotherapy with humanized anti-A $\beta$ monoclonal antibodies}

Intravenous infusion of anti-A $\beta$ antibodies represents an alternative option allowing a more direct control of the therapeutic action. As passive immunotherapy does not raise an endogenous immune response, infusions have to be repeated. Trials with bapineuzumab, 
gantenerumab and solanezumab are the most advanced. ${ }^{8-10}$ Some of them proved efficient at reducing brain amyloid load, ${ }^{9,11}$ or at decreasing Tau and phosphorylated-Tau levels in the CSF without an effect on A $\beta$ peptide level. ${ }^{12}$ The assessment of the clinical response was expected with great interest. Results of phase three studies involving a large number of patients treated with bapineuzumab and solanezumab were released this summer. They indicated that both antibodies failed to show a significant clinical benefit. In patients with mild-to-moderate $\mathrm{AD}$, the primary clinical endpoints, defined by improved cognitive and functional performances compared to placebo, were not met.

2. The inappropriate therapeutic window as the best explanation for the failure of passive anti-A $\beta$ immunotherapy?

Time has come to tentatively interpret these disappointing results. The most likely and considered explanation is that the patients have been treated too late. All antibodies targeted the $\mathrm{A} \beta$ peptide, which is supposedly a central pathophysiological factor involved at early stages of the disease, before the onset of clinical symptoms. Oligomeric forms of $A \beta$ cause both functional and morphological synaptic changes ${ }^{13}$ and are considered the most neurotoxic $\mathrm{A} \beta$ species. ${ }^{14,15}$ In addition, amyloid plaques may be sources of neurotoxic $\mathrm{A} \beta$ aggregates that could be released by exposure to biological lipids. ${ }^{16}$ In vivo imaging study of neuronal activity showed that neurons located in the vicinity of amyloid plaques have abnormal activities. ${ }^{17}$ Considering the potential diverse roles of different $A \beta$ molecular species, the nature of the species preferentially targeted in vivo by each given therapeutic antibody is a key aspect to be taken into consideration, which may have a major impact on the clinical efficacy of such antibody-based immunotherapy strategies. All monoclonal anti-A $\beta$ antibodies are developed today with the aim of binding and neutralizing $A \beta$ before it forms plaques, following the idea that this therapeutic approach could protect the brain at an early stage of the disease, before 
neurodegeneration. From a pathophysiological point of view, this strategy is supported by clinical data showing that amyloid load assessed by PIB-PET remains stable over AD followup and does not correlate with clinical signs of the disease. Amyloid deposits are supposed to play a toxic role before the onset of symptoms, while clinical symptoms rather relate to neurofibrillary tangles. ${ }^{18,19}$ Reinforcing this view, clinical trials with solanezumab seemed to show a relative benefit in mild but not moderate stage of $\mathrm{AD}$. This may be due to the preferential binding of solanezumab to soluble $A \beta$ and its weak affinity for fibrillar forms, whereas bapineuzumab binds amyloid plaques more strongly than soluble $A \beta .^{20}$ In mouse models, previous experiments have shown that some antibodies that bind soluble oligomeric species of $\mathrm{A} \beta$ and have little or no effect on amyloid deposits, are efficient in reversing memory loss. ${ }^{21-23}$

In line with these data, it is almost unanimously admitted that the failure of recent clinical trials of passive anti-A $\beta$-immunotherapy is due at least partly to the inappropriate therapeutic window, which should rather start at an earlier stage of the disease, even before the onset of clinical symptoms. Therefore, Alzheimer's prevention trials in asymptomatic genetic forms of $\mathrm{AD}$ have been launched, and it is now proposed to extend therapeutic trials to cognitively normal individuals suspected to be at an asymptomatic stage of sporadic $\mathrm{AD} .^{24}$

3. What other factors should be considered in anti-A $\beta$ immunotherapy strategies?

Whereas treating patients as early as possible may be a crucial requirement for improving the efficacy of antibody-based strategies, the real clinical impact of such early treatments is still uncertain. Hence, elaborating in parallel the scientific rationale for designing alternative innovative immunotherapy approaches remains necessary. Several factors that may influence the efficiency of anti-A $\beta$ immunotherapy strategies should also be taken into consideration. Regarding the mechanistic bases of immunotherapy, it is worth noting that in initial mouse 
pre-clinical studies based on vaccination with full-length $A \beta_{42},{ }^{1-3}$ immune effector mechanisms actually involved in the observed therapeutic effects had not been investigated: which immune cells where involved? What was the extent and profile of cellular $\mathrm{T}$ cell responses? Most importantly, experimental immunotherapy strategies were evaluated in syngeneic or hybrid mouse strains, i.e. groups of individuals displaying no, or highly restricted, genetic variability. The critical influence of immune response genes and other genetic factors that may modulate the magnitude and functionality of immune responses to $\mathrm{A} \beta$ remained underestimated and unexplored. ${ }^{25}$ Among key aspects, peripheral $\mathrm{T}$ cell responses to $A \beta$ were not assessed in the AN1792 vaccinated patients, and their HLA haplotypes - the polymorphic molecules that condition antigen presentation to $\mathrm{T}$ cells - were not identified. It was generally considered that $\mathrm{T}$ cell responses had to be avoided and that antibodies could be sufficient for mediating the expected therapeutic effect.

Increasing evidences suggest that in vivo inflammatory and spontaneous immune responses are involved in the pathophysiology of the disease ${ }^{26-28}$ and thus likely influence the course of A $\beta$-targeting immunotherapy. Of note, a recent report highlighted a beneficial antiinflammatory effect of $A \beta$ and its potential to alter the expansion or depletion of specific immune cell subsets in a murine model of immune-mediated CNS pathology. ${ }^{29}$ In addition, recent data showed that IL-12/IL-23 signaling plays a role in modulating not only the amount of $A \beta$ plaques, but also the severity of cognitive impairment in murine models of the disease. ${ }^{30}$ Such data emphasize the need for better understanding the role and regulation of inflammatory and $\mathrm{A} \beta$-specific immune responses in $\mathrm{AD}$, including cellular $\mathrm{T}$ cell responses.

Another aspect that deserves attention is the involvement of microvessels and cerebral amyloid angiopathy (CAA) in $\mathrm{A} \beta$ clearance. ${ }^{31} \mathrm{CAA}$ is heterogeneously associated with $\mathrm{AD}$, and its time course remains undetermined. Immunotherapy exacerbates CAA in mouse models and in humans. ${ }^{32}$ Neuropathological examinations suggested that $A \beta$ immunization 
resulted in the solubilisation of plaques-bound $A \beta_{42}$, which at least in part exits the brain via the perivascular pathway, thus transiently increasing the severity of CAA. ${ }^{33}$ Interestingly, recent studies evidenced an implication of $\mathrm{CD}^{+} \mathrm{T}$ cell responses in CAA-related pathologies. ${ }^{34}$ Thus, understanding how the neurovascular unit, i.e. the cerebrovasculature and its associated cells (astrocytes, neurons, pericytes and microglia) are affected during AD progression, the implication of adaptive immune responses in this phenomenon and its impact in immunotherapy, appears essential.

Several clinical aspects pertaining to the early stages of $\mathrm{AD}$ also deserve further attention considering their impact on the design of new therapeutic trials. One critical point relates to the rate of $\mathrm{AD}$ progression, which is heterogeneous across patients, with rapid and slow progressors. ${ }^{35}$ Pathophysiological factors that may account for clinical differences across benign and aggressive forms of $\mathrm{AD}$ could themselves modulate the efficacy of immunotherapy. Apart from age of onset - "subject age is an important factor to consider when defining the study population in AD trials of potential disease-modifying treatment" older age onset being associated with a slower decline, we lack validated prognostic factors for anticipating the severity of clinical decline, the variability of which is more important at a very early stage of AD. Thus, pooling slow and fast progressors could mask the therapeutic effects of drugs.

The idea of extending therapeutic trials to cognitively normal individuals suspected to be at an asymptomatic stage of $\mathrm{AD}$ is now proposed. ${ }^{24}$ Such an asymptomatic stage of the disease is accessible in patients carrying mutations in the presenilin 1 or other genes implicated in familial forms of AD. Whereas the Alzheimer Prevention Initiative seems appropriate in such patients who will inevitably develop $\mathrm{AD}$, extending the same treatment strategy to asymptomatic sporadic AD remains questionable. From a pathophysiological point of view, familial and sporadic cases of $\mathrm{AD}$ cannot be considered similar, displaying for instance 
different patterns of amyloid deposition upon PIB-PET imaging. ${ }^{37}$ From a clinical point of view, the selection criteria for defining the target population have to be carefully defined: is amyloid imaging sufficient to make a diagnosis of asymptomatic AD in cognitively normal individuals without mutation, or is it necessary to combine biomarkers of neurodegeneration or neuronal injury ${ }^{24,38}$ In cognitively normal elderly, a recent report showed that CSF A $\beta$ level correlated with longitudinal cognitive decline only in individuals displaying elevated PTau, whereas low A $\beta$ level alone was not associated with mild cognitive decline during the 3 years of follow-up. ${ }^{39}$ The actual rate of disease occurrence in these supposedly presymptomatic patients remains unknown. Is the risk of developing $\mathrm{AD}$ equal for all "biologically positive" subjects, or is there a "state of resilience"? ${ }^{40}$ The first preventive trial in sporadic AD (A4) with Solanezumab, which should start soon in elderly subjects aged 70 and above displaying evidence of brain amyloid deposition and without clinical symptoms, will help-answering these questions.

The earlier stage of the disease is targeted, the greater is the risk of including heterogeneous patients with different modulating factors and mechanisms associated with amyloid pathology. Hence, stratification of subjects not only based on amyloid and Tau biomarkers, but also on associated factors, such as inflammatory, immune, microvascular and genetic markers should be considered. The perspective of treating asymptomatic patients who are "at risk" for $\mathrm{AD}$ not only raises concerns on costs, but also questions about the design of such clinical trials. The misleading experience in MCI trials with anticholinesterasic drugs, which did not change the conversion rate to dementia, should be kept in mind. In these trials MCI was considered an homogeneous risk factor for AD. We now know that it is not the case, as MCI can be related to different possible pathological substrates. This bias is now minimized by using pathophysiological markers of $\mathrm{AD}$, which increases the accuracy of the clinical diagnosis. 
In conclusion, the consideration of many unforeseen aspects seems required for the proper development and clinical evaluation of efficient and safe immunotherapies in AD. Whereas targeting patients at asymptomatic stages of the disease, as envisioned in the A4 and Alzheimer Prevention Trials, is a critical step in the goal of improving the efficiency of antiA $\beta$ antibody-based immunotherapy approaches, the real clinical impact of such early treatments is still uncertain. As we intended to show here, AD is a complex puzzle and, in spite of numerous efforts, its relationship with the immune system remains poorly understood. Because the neuroprotective potential of both innate and adaptive immune responses has been demonstrated in several neurodegenerative conditions, ${ }^{41,}{ }^{42}$ their role and interplay in the pathophysiology of AD need to be further elucidated. Such studies appear crucial for fine tuning the design of innovative immunotherapy strategies as well as properly defining the target populations for clinical testing. Importantly, several alternative or combinatorial approaches should be considered, which would possibly imply other effectors than antibodies. Taking into account these unforeseen aspects of $\mathrm{AD}$ together with what we have learned from a ten year-experience of anti-A $\beta$ immunotherapy may be the golden path to the development of immune-based disease-modifying treatments for AD.

\section{Acknowledgements}

We thank Charles Duyckaerts for critical reading of the manuscript and fruitful comments. 


\section{References}

1. Janus C, Pearson J, McLaurin J, et al. A beta peptide immunization reduces behavioural impairment and plaques in a model of Alzheimer's disease. Nature 2000; 408(6815): 979-82.

2. Morgan D, Diamond DM, Gottschall PE, et al. A beta peptide vaccination prevents memory loss in an animal model of Alzheimer's disease. Nature 2000; 408(6815): 982-5.

3. Schenk D, Barbour R, Dunn W, et al. Immunization with amyloid-beta attenuates Alzheimer-disease-like pathology in the PDAPP mouse. Nature 1999; 400(6740): 173-7.

4. Gilman S, Koller M, Black RS, et al. Clinical effects of Abeta immunization (AN1792) in patients with AD in an interrupted trial. Neurology 2005; 64(9): 1553-62.

5. Orgogozo JM, Gilman S, Dartigues JF, et al. Subacute meningoencephalitis in a subset of patients with AD after Abeta42 immunization. Neurology 2003; 61(1): 46-54.

6. Holmes C, Boche D, Wilkinson D, et al. Long-term effects of Abeta42 immunisation in Alzheimer's disease: follow-up of a randomised, placebo-controlled phase I trial. Lancet 2008; 372(9634): 216-23.

7. Winblad B, Andreasen N, Minthon L, et al. Safety, tolerability, and antibody response of active Abeta immunotherapy with CAD106 in patients with Alzheimer's disease: randomised, double-blind, placebo-controlled, first-in-human study. Lancet Neurol 2012; 11(7): 597-604.

8. Farlow M, Arnold SE, van Dyck $\mathrm{CH}$, et al. Safety and biomarker effects of solanezumab in patients with Alzheimer's disease. Alzheimers Dement 2012; 8(4): 261-71.

9. Ostrowitzki S, Deptula D, Thurfjell L, et al. Mechanism of amyloid removal in patients with Alzheimer disease treated with gantenerumab. Arch Neurol 2012; 69(2): 198207.

10. Salloway S, Sperling R, Gilman S, et al. A phase 2 multiple ascending dose trial of bapineuzumab in mild to moderate Alzheimer disease. Neurology 2009; 73(24): 2061-70.

11. Rinne JO, Brooks DJ, Rossor MN, et al. 11C-PiB PET assessment of change in fibrillar amyloid-beta load in patients with Alzheimer's disease treated with bapineuzumab: a phase 2, double-blind, placebo-controlled, ascending-dose study. Lancet Neurol 2010; 9(4): 363-72.

12. Blennow $\mathrm{K}$, Zetterberg $\mathrm{H}$, Rinne JO, et al. Effect of immunotherapy with bapineuzumab on cerebrospinal fluid biomarker levels in patients with mild to moderate Alzheimer disease. Arch Neurol 2012; 69(8): 1002-10. 
13. LaFerla FM, Green KN, Oddo S. Intracellular amyloid-beta in Alzheimer's disease. Nat Rev Neurosci 2007; 8(7): 499-509.

14. Klyubin I, Walsh DM, Lemere CA, et al. Amyloid beta protein immunotherapy neutralizes Abeta oligomers that disrupt synaptic plasticity in vivo. Nat Med 2005; 11(5): 556-61.

15. Lesne S, Koh MT, Kotilinek L, et al. A specific amyloid-beta protein assembly in the brain impairs memory. Nature 2006; 440(7082): 352-7.

16. Martins IC, Kuperstein I, Wilkinson H, et al. Lipids revert inert Abeta amyloid fibrils to neurotoxic protofibrils that affect learning in mice. EMBO J 2008; 27(1): 224-33.

17. Rudinskiy N, Hawkes JM, Betensky RA, et al. Orchestrated experience-driven Arc responses are disrupted in a mouse model of Alzheimer's disease. Nature neuroscience 2012; 15(10): 1422-9.

18. de Souza LC, Corlier F, Habert MO, et al. Similar amyloid- $\{$ beta $\}$ burden in posterior cortical atrophy and Alzheimer's disease. Brain 2011; 134(Pt 7): 2036-43.

19. Klunk WE, Mathis CA, Price JC, Lopresti BJ, DeKosky ST. Two-year follow-up of amyloid deposition in patients with Alzheimer's disease. Brain 2006; 129(Pt 11): 2805-7.

20. Callaway E. Alzheimer's drugs take a new tack. Nature 2012; 489(7414): 13-4.

21. Dodart JC, Bales KR, Gannon KS, et al. Immunization reverses memory deficits without reducing brain Abeta burden in Alzheimer's disease model. Nature neuroscience 2002; 5(5): 452-7.

22. Kotilinek LA, Bacskai B, Westerman M, et al. Reversible memory loss in a mouse transgenic model of Alzheimer's disease. J Neurosci 2002; 22(15): 6331-5.

23. Lee EB, Leng LZ, Zhang B, et al. Targeting amyloid-beta peptide (Abeta) oligomers by passive immunization with a conformation-selective monoclonal antibody improves learning and memory in Abeta precursor protein (APP) transgenic mice. The Journal of biological chemistry 2006; 281(7): 4292-9.

24. Sperling RA, Karlawish J, Johnson KA. Preclinical Alzheimer disease-the challenges ahead. Nat Rev Neurol 2012; 9(1): 54-8.

25. Toly-Ndour C, Lui G, Nunes MM, Bruley-Rosset M, Aucouturier P, Dorothee G. $\mathrm{MHC}$-independent genetic factors control the magnitude of $\mathrm{CD} 4+\mathrm{T}$ cell responses to amyloid-beta peptide in mice through regulatory T cell-mediated inhibition. J Immunol 2011; 187(9): 4492-500.

26. Dorothee G, Bottlaender M, Moukari E, et al. Distinct patterns of antiamyloid-beta antibodies in typical and atypical Alzheimer disease. Arch Neurol 2012; 69(9): 1181-5.

27. Huang X, Reynolds AD, Mosley RL, Gendelman HE. CD 4+ T cells in the pathobiology of neurodegenerative disorders. J Neuroimmunol 2009; 211(1-2): 3-15.

28. Wyss-Coray $\mathrm{T}$. Inflammation in Alzheimer disease: driving force, bystander or beneficial response? Nat Med 2006; 12(9): 1005-15.

29. Grant JL, Ghosn EE, Axtell RC, et al. Reversal of paralysis and reduced inflammation from peripheral administration of beta-amyloid in TH1 and TH17 versions of experimental autoimmune encephalomyelitis. Science translational medicine 2012; 4(145): 145ra05.

30. Vom Berg J, Prokop S, Miller KR, et al. Inhibition of IL-12/IL-23 signaling reduces Alzheimer's disease-like pathology and cognitive decline. Nat Med 2012; 18(12): 1812-9.

31. Weller RO, Boche D, Nicoll JA. Microvasculature changes and cerebral amyloid angiopathy in Alzheimer's disease and their potential impact on therapy. Acta Neuropathol 2009; 118(1): 87-102.

32. Wilcock DM, Colton CA. Immunotherapy, vascular pathology, and microhemorrhages in transgenic mice. CNS \& neurological disorders drug targets 2009; 8(1): 50-64.

33. Boche D, Zotova E, Weller RO, et al. Consequence of Abeta immunization on the vasculature of human Alzheimer's disease brain. Brain 2008; 131(Pt 12): 3299-310. 
34. Melzer N, Harder A, Gross CC, et al. CD4(+) T cells predominate in cerebrospinal fluid and leptomeningeal and parenchymal infiltrates in cerebral amyloid beta-related angiitis. Arch Neurol 2012; 69(6): 773-7.

35. Kinkingnehun S, Sarazin M, Lehericy S, Guichart-Gomez E, Hergueta T, Dubois B. VBM anticipates the rate of progression of Alzheimer disease: a 3-year longitudinal study. Neurology 2008; 70(23): 2201-11.

36. Bernick C, Cummings J, Raman R, Sun X, Aisen P. Age and rate of cognitive decline in Alzheimer disease: implications for clinical trials. Arch Neurol 2012; 69(7): 901-5.

37. Knight WD, Okello AA, Ryan NS, et al. Carbon-11-Pittsburgh compound B positron emission tomography imaging of amyloid deposition in presenilin 1 mutation carriers. Brain 2011; 134(Pt 1): 293-300.

38. Sperling RA, Aisen PS, Beckett LA, et al. Toward defining the preclinical stages of Alzheimer's disease: Recommendations from the National Institute on Aging-Alzheimer's Association workgroups on diagnostic guidelines for Alzheimer's disease. Alzheimers Dement 2011; 7(3): 280-92.

39. Desikan RS, McEvoy LK, Thompson WK, et al. Amyloid-beta--associated clinical decline occurs only in the presence of elevated P-tau. Arch Neurol 2012; 69(6): 709-13.

40. Driscoll I, Troncoso J. Asymptomatic Alzheimer's disease: a prodrome or a state of resilience? Curr Alzheimer Res 2011; 8(4): 330-5.

41. Kipnis J, Cohen H, Cardon M, Ziv Y, Schwartz M. T cell deficiency leads to cognitive dysfunction: implications for therapeutic vaccination for schizophrenia and other psychiatric conditions. Proc Natl Acad Sci U S A 2004; 101(21): 8180-5.

42. Schwartz M, Shechter R. Systemic inflammatory cells fight off neurodegenerative disease. Nat Rev Neurol 2010; 6(7): 405-10. 